\title{
Mechanochemical Synthesis and Spark Plasma Sintering of the Cerium Silicides
}

Gordon A. Alanko ${ }^{1}$, Brian Jaques ${ }^{1}$, Allyssa Bateman ${ }^{1}$ and Darryl P. Butt ${ }^{1,2, *}$

1. Department of Materials Science and Engineering, College of Engineering Boise State University, 1910 University Drive, Boise, ID, 83725

2. Center for Advanced Energy Studies

995 University Boulevard, Idaho Falls, ID 83401

The cerium silicides, $\mathrm{Ce}_{5} \mathrm{Si}_{3}, \mathrm{Ce}_{3} \mathrm{Si}_{2}, \mathrm{CeSi}, \mathrm{CeSi}_{2-y}$, and $\mathrm{CeSi}_{2-x}$, have been prepared from the elements by mechanochemical processing in a planetary ball mill. Preparation of the cerium silicide $\mathrm{Ce}_{5} \mathrm{Si}_{4}$ was unsuccessfully attempted and potential reasons for this are discussed. Temperature and pressure of the milling vial were monitored in situ to gain insight into the mechanochemical reaction kinetics, which include a mechanically-induced self-propagating reaction (MSR). Some prepared powders were consolidated by spark plasma sintering to high density. Starting materials, as-milled powders, and consolidated samples were characterized by $x$-ray diffraction, scanning electron microscopy, and energy dispersive spectroscopy. The results obtained help elucidate key questions in mechanochemical processing of intermetallics, showing first phase formation similar to thin films, MSR ignition times that are composition- and milling speed-dependent, and sensitivity of stable compound formation on the impact pressure. The results demonstrate mechanochemical synthesis as a viable technique for rare earth silicides.

Keywords: mechanochemistry, silicides, rare earths, high energy ball milling, spark plasma sintering

- Author to whom correspondence should be addressed at darrylbutt@boisestate.edu

1

(C) 2014. This manuscript version is made available under the Elsevier user license http://www.elsevier.com/open-access/userlicense/1.0/ 


\section{Introduction}

Rare earth silicides have been studied for many years because of their interesting electromagnetic properties, utility in semiconductor devices, refractory nature, and for the ability of some silicides to form oxidation resistant protective silica films. Cerium is well known among the rare earths for forming compounds with complicated magnetic behavior, and binary and ternary compositions near $\mathrm{CeSi}_{2}$ have received considerable attention for their magnetic properties ${ }^{1,2} \cdot \mathrm{Ce}_{3} \mathrm{Si}_{2}$ is isostructural with $\mathrm{U}_{3} \mathrm{Si}_{2}{ }^{3}$, and may be a potential surrogate for studies of processing techniques, oxidation, corrosion, and transport properties in this important compound. Meanwhile, $\mathrm{CeSi}, \mathrm{Ce}_{5} \mathrm{Si}_{4}$, and ternary compounds based on $\mathrm{Ce}_{5} \mathrm{Si}_{4}$ have been studied as magnetocaloric materials for refrigeration ${ }^{4,5}$. The compounds of cerium with silicon are commonly prepared by arc melting the elements, with the cast buttons used as-is or as master alloys for single crystal growth ${ }^{2}$. This process may dissolve oxygen or volatilize cerium or silicon as $\mathrm{MO}$ species, resulting in off-stoichiometric products.

Here we describe the preparation of the entire range of cerium silicides by high energy ball milling (HEBM), which is a self-enclosed processing technique that can limit oxygen contamination and cerium or silicon loss. The HEBM technique has been used to synthesize many materials including oxide dispersion strengthened steel alloys ${ }^{6}$ and many intermetallics ${ }^{7}$. The preparation of silicides by HEBM was first reported nearly thirty years ago ${ }^{8,9}$, and the technique has since been applied to many silicide systems. Some silicides with a high enthalpy of formation, such as $\mathrm{MoSi}_{2}$, exhibit a sudden reaction during HEBM in a process termed mechanochemically-induced self-propagating reaction (MSR) ${ }^{10}$. Takacs adapted the criterion ${ }^{11}$ for self-propagating high-temperature synthesis to predict MSR to occur in systems with an adiabatic reaction temperature $>2000 \mathrm{~K}$. The adiabatic temperature is given by $T_{A D}=$ $\Delta H_{f}\left(T_{r \times n}\right) / C_{P}\left(T_{r x n}\right)$, where $\Delta H_{f}$ and $C_{p}$ are the respective reaction enthalpy and heat capacity of the formed compound at the temperature of the reaction. The ratio $\Delta \mathrm{H}_{\mathrm{f}}^{298} / \mathrm{C}_{\mathrm{p}}$ is assumed to be a close approximation to the high temperature value $\Delta H_{f}\left(T_{r x n}\right) / C_{P}\left(T_{r x n}\right)$ as high temperature properties are not well known in many systems. A similar condition requires $\mathrm{T}_{\mathrm{AD}}$ to exceed the melting temperature of at least one constituent. The Ce-Si system is uncommon in the fact that all line compounds have $\Delta \mathrm{H} / \mathrm{Cp}>$ $2000 \mathrm{~K}$, as shown in Table 1, making the Ce-Si system ideal for investigating MSR-type behavior in systems with multiple intermetallic compounds.

Table 1 lists the compounds in the Ce-Si system that are relevant to the temperature range of ball milling, along with heats of formation $\Delta \mathrm{H}_{\mathrm{f}}^{29812,13}$, calculated adiabatic reaction temperatures $\mathrm{T}_{\mathrm{AD}}$, effective heats of formation $\Delta \mathrm{H}_{\mathrm{f}}{ }^{14}$, and crystallographic information ${ }^{3}$. Heats of formation are used rather than free energies because the product $-\mathrm{T} \Delta \mathrm{S}$ is small for solid state reactions near room temperature and the free energy may thus be approximated by $\Delta \mathrm{H}_{\mathrm{f}}$. The effective heat of formation is defined as $\Delta \mathrm{H}_{\mathrm{f}}{ }^{\prime}=\Delta \mathrm{H}_{\mathrm{f}}\left(\mathrm{x}^{\prime} / \mathrm{x}\right)$ where $\mathrm{x}$ is the limiting reactant at the nominal composition, and $\mathrm{x}^{\prime}$ is the limiting reactant at the composition of the lowest melting eutectic. For the crystallographic data we adopt a formalism in which $\mathrm{CeSi}_{2-x}$ denotes the silicon deficient $\alpha-\mathrm{ThSi}_{2}$ prototype compound spanning the composition range $\mathrm{CeSi}_{1.81}-\mathrm{CeSi}_{2}{ }^{2}$. Likewise, $\mathrm{CeSi}_{2-y}$ denotes the $\alpha-\mathrm{GdSi}_{2}$ prototype, which melts congruently at $\mathrm{CeSi}_{1.81}$ but has been reported to have a greatly increased homogeneity range when equilibrated in the range $800-1100^{\circ} \mathrm{C}^{15,16}$. 
Table 1: Thermodynamic and Crystallographic data for the Ce-Si system

\begin{tabular}{|c|c|c|c|c|c|c|}
\hline Species $^{3}$ & $\mathrm{CeSi}_{2-x}$ & $\mathrm{CeSi}_{2-y}$ & $\mathrm{CeSi}$ & $\mathrm{Ce}_{5} \mathrm{Si}_{4}$ & $\mathrm{Ce}_{3} \mathrm{Si}_{2}$ & $\mathrm{Ce}_{5} \mathrm{Si}_{3}$ \\
\hline Formation $^{3}$ & Peritectic & Congruent & Congruent & Peritectic & Peritectic & Peritectic \\
\hline Unit cell ${ }^{3}$ & Tetragonal & Orthorhombic & Orthorhombic & Tetragonal & Tetragonal & Tetragonal \\
\hline Space Group ${ }^{17}$ & $14_{1} /$ amd & Imma & Pnma & $\mathrm{P} 4{ }_{1} 2{ }_{1} 2$ & $\mathrm{P} 4 / \mathrm{mbm}$ & $14 / \mathrm{mcm}$ \\
\hline Prototype $^{17}$ & $\alpha-\mathrm{ThSi}_{2}$ & $\alpha-\mathrm{GdSi}_{2}$ & $\mathrm{FeB}$ & $\mathrm{Zr}_{5} \mathrm{Si}_{4}$ & $\mathrm{U}_{3} \mathrm{Si}_{2}$ & $\mathrm{~W}_{5} \mathrm{Si}_{3}$ \\
\hline Volume $\left(\mathrm{cm}^{3} / \mathrm{mol}\right)^{17}$ & 36.21 & 36.3 & 29.42 & 143.56 & 79.77 & 129.05 \\
\hline$\Delta V / V_{0}(\%)$ & -24.4 & -13.5 & -12.2 & -6.5 & -9 & -9.2 \\
\hline$\Delta \mathrm{H}_{\mathrm{f}}^{298}\left(\mathrm{~kJ} / \mathrm{mol}_{13} \text { atom }\right)^{12}$ & -62.7 & -68.1 & -70.5 & -65.7 & -60.9 & -57.2 \\
\hline$T_{A D}=\Delta H / C_{P}(K)$ & 2829 & 3033 & 3017 & 2764 & 2529 & 2359 \\
\hline$\Delta \mathrm{H}_{\mathrm{f}}^{\prime}(\mathrm{kJ} / \mathrm{mol}$ atom $)$ & -16.0 & -16.0 & -15.5 & -14.8 & -11.1 & -9.9 \\
\hline
\end{tabular}

\section{Materials and Methods}

The starting materials were cerium filings (99.9\%, ESPI Metals, USA) and silicon powder (1-20 $\mu \mathrm{m}$, 99.9995\%, Alfa Aesar, USA). The cerium filings were supplied at -40 mesh, and were further graded to +60 (corresponding to screened particle sizes of $420-250 \mu \mathrm{m}$ ) before conducting experiments. X-ray diffraction (XRD) analyses showed the cerium to be phase pure to within the detection limit of the XRD, while the silicon was phase pure with a low amorphous background. All experiments were performed with a planetary ball mill (Retsch PM100, Germany) with a $250 \mathrm{~mL}$ hardened steel milling vessel and ceria-stabilized zirconia milling (CSZ) media of 5 and $10 \mathrm{~mm}$ diameter. Before beginning experiments, the volume of the milling vessel after sealing the attached lid was calculated to be $274 \mathrm{~mL}$ by measuring the amount of deionized water required to completely fill the assembly. The pressure and temperature within the vessel during milling were monitored in situ by sensors mounted in the milling vessel lid. The pressure sampling rate was $2 \mathrm{~s}^{-1}$ and temperature sampling rate was $1 \mathrm{~s}^{-1}$. The ambient pressure and temperature near the mill was sampled by a benchtop datalogger at 10 minute intervals in order to separate any effect of the ambient conditions on the data collected in-situ during milling.

After each milling run in which pressure and temperature were monitored, the vessel was allowed to cool to ambient temperature. The milling run was then repeated without opening the jar to allow for the separation of the effects of chemical reaction(s) from that of mechanical heating of the milling jar. Milled silicides with higher cerium contents than that of CeSi tended to adhere to the milling vessel walls. To clean the vessel when changing from one nominal composition to another, the milling vessel volume was filled $2 / 3$ full with CSZ media and $20 \mathrm{~mL}$ isopropyl alcohol and milled for 5 minutes at 500 rpm. This treatment was sufficient to removed gross deposits of silicide. Media were cleaned of adhered silicide between milling experiments of identical compositions by another 5 minute milling in isopropyl alcohol, and fresh media were substituted when changing compositions. As-milled powders were screened to -120 mesh and stored in an argon-atmosphere glovebox. Some as-milled powder was consolidated into dense pellets by spark plasma sintering (SPS) (Dr. Sinter SPS-550, Fuji Corp., Japan) for 
further experiments and microstructural characterization of the monolithic product. Experimental Procedures

In a typical milling experiment, $5 \mathrm{~g}$ of the elemental starting materials were weighed and added to the milling vessel along with fifteen $10 \mathrm{~mm}$ and ten $5 \mathrm{~mm}$ media in an argon atmosphere glovebox with $\mathrm{P}_{\mathrm{O} 2}<30 \mathrm{ppm}$, resulting in a ball-to-powder ratio of approximately 10:1. Different sized media were used in order to randomize milling media trajectories and help ensure that no portion of the vessel contained unmilled material. Milling was conducted at $500 \mathrm{rpm}$ for between 5 minutes and 8 hours. At least two experiments were conducted at the nominal composition of each line compound in Table 1, as well as at the nominal compositions identified as the middle eutectic ( $55 \% \mathrm{Si}, \mathrm{CeSi}_{1.23}$ ) and near the Si-poor boundary of the $\mathrm{CeSi}_{2-y}$ phase $\left(61 \% \mathrm{Si}, \mathrm{CeSi}_{1.56}\right)$.

In a typical SPS experiment, $4 \mathrm{~g}$ of milled powder was loaded into a graphite die (I-85, Electrodes Inc, USA) in a nitrogen atmosphere glovebox with $\mathrm{P}_{02}<200 \mathrm{ppm}$. Samples were cold pressed at $5 \mathrm{kN}$ in the die and then transported to the SPS in a polyethylene bag. The graphite dies had a $21 \mathrm{~mm}$ bore and $15 \mathrm{~mm}$ thick wall and were lined with grafoil (99.8\%, Alfa Aesar, USA). Samples were heated at $100^{\circ} \mathrm{C} / \mathrm{min}$ to $1000-1300^{\circ} \mathrm{C}$ with a 5-15 minute hold. Process temperature was controlled by a pyrometer focused in a $5 \mathrm{~mm}$ bore hole drilled to within $5 \mathrm{~mm}$ of the sample. Samples were pre-loaded at $5 \mathrm{kN}$ in the SPS apparatus and held at $5 \mathrm{kN}$ throughout the temperature ramp until cooldown. Sintered samples of $\mathrm{CeSi}_{2-x}, \mathrm{CeSi}$, and $\mathrm{Ce}_{3} \mathrm{Si}_{2}$ were prepared in this manner.

The crystallite size and phase of starting materials, as-milled powder, and sintered pellets were characterized by XRD in Bragg-Brentano geometry (Rigaku Miniflex, Japan). To avoid excessive oxidation, powder samples were mixed with a small amount of vacuum grease under argon before loading the XRD sample holder. A single peak was noted at $28.1^{\circ} 2 \theta$ when characterizing a blank slide containing only vacuum grease. Phase identification was performed by comparison to the Inorganic Crystal Structure Database ${ }^{17}$. Microstructure and morphology were investigated by scanning electron microscopy and stoichiometry by energy dispersive spectroscopy (Hitachi 3400-N, Japan). EDS spectra were collected with an accelerating voltage of $10 \mathrm{kV}$ to improve surface selectivity and sensitivity to silicon content.

\section{Results}

\subsection{Pressure and Temperature Monitoring Results}

The in situ monitoring of temperature and pressure revealed a small spike in pressure between 30 minutes and 150 minutes of milling at $500 \mathrm{rpm}$. The exact location depended on the composition, and the occurrence, height, and timing of the spike was repeatable to within $10 \%$ relative error from run to run. Representative data for four different compositions are shown in Figure 1, with details of the $\Delta T$ calculation given in the discussion section. The inset shows a very nearly linear dependence of milling time before reaction on milling speed for the CeSi composition.

\subsection{Milling Results}


All of the line compounds in the Ce-Si system except $\mathrm{Ce}_{5} \mathrm{Si}_{4}$ were successfully synthesized by high-energy ball milling at $500 \mathrm{rpm}$. Representative diffraction plots for the each composition are shown in Figure 2. XRD analysis of $\mathrm{CeSi}_{2}$ showed a small amount of unreacted cerium, which was determined to be a consequence of a small amount of material that became trapped in the vessel lid seal during milling. No impurity phase was detected in XRD of $\mathrm{CeSi}_{1.68}, \mathrm{Ce}_{3} \mathrm{Si}_{2}$ and $\mathrm{Ce}_{5} \mathrm{Si}_{3}$. The XRD pattern for CeSi matched the peak locations in the database but not intensities, implying a change in structure from the Pbma orthorhombic phase commonly observed when cooling from the melt. There is precedence for formation of low-temperature (LN)Si phases in the lanthanides, although none have yet been reported for $\mathrm{CeSi}$. The nominal composition $\mathrm{Ce}_{5} \mathrm{Si}_{4}$ showed the presence of $\mathrm{CeSi}$ and $\mathrm{Ce}_{3} \mathrm{Si}_{2}$ phases with little to no $\mathrm{Ce}_{5} \mathrm{Si}_{4}$. EDS investigation found minimal contamination of $<1 \% \mathrm{Zr}$ and Fe from the milling media and vessel, respectively, after 6 hours of milling at $500 \mathrm{rpm}$. Figure 3 shows material with nominal composition $\mathrm{Ce}_{3} \mathrm{Si}_{2}$ as sampled just before (Figure 3c) and just after (Figure 3a,b) the P/T spike shown in Figure 1.

\subsection{Spark Plasma Sintering Results}

A representative plot of the sintering temperature, pressure, and punch displacement during densification of a $\mathrm{Ce}_{3} \mathrm{Si}_{2}$ powder milled for $4 \mathrm{hr}$ at $500 \mathrm{rpm}$ is shown in Figure 4. Densification was nearly complete by $1000^{\circ} \mathrm{C}$, indicated by the decrease in densification rate near the end of the temperature ramp. Spark plasma sintered samples, phase pure by XRD, were found to be greater than $95 \%$ of the theoretical density by the Archimedes method. Samples had a thin interaction layer with the grafoil liner (not shown) that was easily removed by polishing. A representative SEM micrograph of a fracture surface is shown in Figure 5, demonstrating the high density and very fine grain structure of the sintered material.

\section{Discussion}

\subsection{In-situ Pressure and Temperature Measurements}

For each milling run, the equilibrium temperature and pressure prior to the start of milling was used to calculate the constant $\mathrm{P} / \mathrm{T}=\mathrm{nR} / \mathrm{V}$ for each experiment, where $\mathrm{P}$ and $\mathrm{T}$ are the measured pressure and temperature, $\mathrm{V}$ and $\mathrm{n}$ are the volume of the milling vessel and the moles of gas contained within, and $\mathrm{R}$ is the gas constant. This constant was then used to calculate the instantaneous temperature from the measured pressure throughout the milling experiment. The primary heat loss is convective cooling, which means that both the measured pressure and temperature are sensitive to the ambient temperature. However, the quantity $\Delta T$ calculated by subtracting the measured temperature from that calculated from the pressure is not particularly sensitive to the ambient T. Converting the P-T data to $\Delta \mathrm{T}$ data in this manner is particularly convenient as it allows for estimation of the energy flux through the system, which may be used to identify transient energy supplied by chemical reactions. Representative plots of raw P-T-t data and a further explanation of the transformation to $\Delta \mathrm{T}$ data is provided as supplementary information.

\subsection{Phase Formation During Milling}


Table 2 presents data on the mass of powder both free in the vessel and adhered to media or vessel walls. These data demonstrate that the adhesion of milled material to the media is minimal prior to the MSR event for the $\mathrm{Ce}_{3} \mathrm{Si}_{2}$ composition (it is also minimal in the other compositions, not shown). This implies that the MSR events indicated by arrows in Figure 1 occur in the free volume of the milling vessel. However, some cerium should be expected to adhere to the milling media, resulting in a siliconrich free powder. A reaction propagating through powder filling free space in the vessel would then produce a silicon-rich composition there, and a cerium-rich composition on the surface of the media and vessel. In fact, in no composition did the MSR event result in complete formation of the expected compound. The furthest extent was reached for the CeSi composition, in which the products directly after MSR were $\mathrm{Ce}_{5} \mathrm{Si}_{3}$ and $\mathrm{CeSi}_{2-\mathrm{x}}$. Other compositions display quenching behavior in which the MSR reaction is initiated, resulting in a brief spike in pressure, but the excess reactant absorbs more energy than the reaction can supply. In these cases the MSR peak is followed by a broad hump in $\Delta T$ as the system components continue to react in the solid state. A similar observation of "slow MSR" in the Zn-S system has been explained as being limited by melting of one reaction component at the point of reaction ${ }^{18}$. As the post-MSR microstructure in the present system shows signs of melting, it is likely that the fast MSR is quenched in similar fashion in the Ce-Si system.

The Effective Heat of Formation (EHF) model has proven quite successful at predicting the first phase formation in interfacial or thin film reactions involving silicon ${ }^{14}$. The effective heat of formation is found as $\Delta H_{f}^{\prime}=\Delta H_{f}\left(x^{\prime} / x\right)$ where $\left(x^{\prime} / x\right)$ is the number of moles of the nominal composition $A_{1-x} B_{x}$ that formed if the reaction proceeds to completion at the composition of the lowest melting eutectic $A_{1-x^{\prime}} B_{x^{\prime}}$. The predicted first phase formed is the congruent melting compound with the most negative $\Delta \mathrm{H}_{f}^{\prime}$ at the eutectic composition. There are three eutectic points in the Ce-Si system, with the lowest melting of these observed at 10.5 at $\% \mathrm{Ce}^{3}$. EDS data (from the sample shown in Figure $3 a, b$ ) shows silicide grains surrounded by cerium metal containing approximately 10 atom \% silicon. This data supports the assumption that a eutectic phase is formed during the MSR event. Therefore, the limiting element $x^{\prime}$ is assumed by the EHF model is $\mathrm{Si}=10.5$ at \% for all compositions and the effective heat of formation for each compound is given by:

$$
\Delta H_{f}^{\prime}\left(C e_{x} S i_{y}\right)=\Delta H_{f}^{298}\left(C e_{x} S i_{y}\right) 0.105\left(\frac{x+y}{y}\right)
$$

The first formed phase predicted by the EHF model has the most negative $\Delta \mathrm{H}_{\mathrm{f}}{ }^{\prime}$. However, the existing literature reports $\mathrm{CeSi}_{2-y}(y \approx 0.3)$ for thin Ce films in contact with silicon ${ }^{19,20}$, and in the present case $\mathrm{CeSi}_{2-y}(y \approx 0.5)$ is observed as the first phase. The first formation of a phase with the silicon-deficient $\mathrm{CeSi}_{2-y}$ orthorhombic crystal structure appears to be a failure of the EHF model in this case, which may indicate errors in the literature heats of formation, or it may be that nucleation of CeSi is kinetically unfavorable. Despite the shortcomings of the model in this case, the calculated values of $\Delta \mathrm{H}_{\mathrm{f}}^{\prime}$ listed in Table 1 correlate remarkably well with the experimentally observed time of MSR ignition at each composition as shown in Figure 6. We therefore suggest that the EHF model, which was developed for thin films, is also an effective tool for predicting the behavior of milled material systems with multiple binary compounds. 
All milling experiments examined in SEM/EDS after an MSR event contained a phase with approximate composition $\mathrm{Ce}_{2} \mathrm{Si}_{3}$. Cerium-rich compositions contained inhomogeneous regions of elemental silicon and what appeared to be a Ce-Si eutectic phase with 10-20 atom \% Si (Figure 3 shows an example for the $\mathrm{Ce}_{3} \mathrm{Si}_{2}$ composition). The CeSi composition was found to consist of $\mathrm{Ce}_{5} \mathrm{Si}_{3}$ and $\mathrm{Ce}_{2} \mathrm{Si}_{3}$ directly after the MSR event. This may be explained by the presence of local inhomogeneity within the milling vessel. Some cerium will always stick to the milling media and will form a cerium rich phase during any nearly complete reaction. This in turn results in formation of a Si-rich phase in the free volume of the milling jar, followed by a relatively quick mechanochemical reaction of the two phases to form the desired compound. In compositions further from CeSi with its nearly complete MSR behavior, the total amount of off-stoichiometric compounds formed is larger, leading to an increase in width of the post-MSR humps observed in Figure 1. Table 2 lists some data versus milling time for the $\mathrm{Ce}_{3} \mathrm{Si}_{2}$ composition, showing the phase progression with increasing milling time as well as the physical location of the milled material within the vessel.

Table 2: Phase and powder habit for nominal composition $\mathrm{Ce}_{3} \mathrm{Si}_{2}$ at different milling times

\begin{tabular}{|c|c|c|c|c|c|c|c|}
\hline Milling Time & $0 \mathrm{~min}$ & $30 \mathrm{~min}$ & $35 \mathrm{~min}$ (MSR) & $60 \mathrm{~min}$ & $90 \mathrm{~min}$ & $120 \mathrm{~min}$ & $360 \mathrm{~min}$ \\
\hline $\begin{array}{l}\text { Phase content } \\
\text { (XRD/EDS) }\end{array}$ & $\mathrm{Ce}, \mathrm{Si}$ & $\mathrm{Ce}, \mathrm{Si}$ & $\begin{array}{c}\mathrm{Ce}, \mathrm{Ce}_{2} \mathrm{Si}_{3} \\
\text { minor } \mathrm{Si}, \mathrm{Ce}_{5} \mathrm{Si}_{3}\end{array}$ & $\begin{array}{l}\mathrm{Ce}, \mathrm{Ce}_{3} \mathrm{Si}_{2} \\
\mathrm{CeSi}, \mathrm{Ce}_{2} \mathrm{Si}_{3} \\
\end{array}$ & $\begin{array}{c}\mathrm{Ce}, \mathrm{Ce}_{3} \mathrm{Si}_{2}, \\
\mathrm{CeSi}\end{array}$ & $\begin{array}{l}\mathrm{Ce}, \mathrm{Ce}_{3} \mathrm{Si}_{2} \\
\text { minor } \mathrm{CeSi}\end{array}$ & $\mathrm{Ce}_{3} \mathrm{Si}_{2}$ \\
\hline Free powder $\mathrm{m}_{\mathrm{f}}(\mathrm{g})$ & 5 & 4.60 & 0.57 & 1.40 & 2.16 & 2.45 & 2.55 \\
\hline Free powder (\%) & 100 & 92 & 11 & 28 & 43 & 49 & 51 \\
\hline Powder on media $\mathrm{m}_{\mathrm{m}}(\mathrm{g})$ & 0.00 & 0.10 & 2.83 & 1.49 & 0.44 & 0.34 & 0.39 \\
\hline Powder on media (\%) & 0 & 2 & 57 & 30 & 9 & 7 & 8 \\
\hline Powder on vessel $m_{v}(g)^{b}$ & 0.10 & 0.30 & 1.60 & 2.11 & 2.40 & 2.21 & 2.06 \\
\hline Powder on vessel (\%) & 3 & 6 & 32 & 42 & 48 & 44 & 41 \\
\hline Particle size $(\mu \mathrm{m})$ & 480 & -- & $>1000$ & -- & -- & -- & 10 \\
\hline Particle morphology & Filings & Sheets & Adherent coating & -- & -- & -- & Equiaxed \\
\hline
\end{tabular}

a. All contain ppm $\mathrm{CeO}_{2}$ from $\mathrm{O}_{2}$ exposure as well as approximately $0.1 \% \mathrm{ZrO}_{2}$ and Fe from milling Powder on vessel $m_{v}$ calculated from $m_{i}-m_{f}-m_{m}=m_{v}$

\subsection{Volume Effects in Milling Thermodynamics}

All cerium silicide line compounds except $\mathrm{Ce}_{5} \mathrm{Si}_{4}$ were prepared by milling for 6 hours or less at $500 \mathrm{rpm}$. The inability to easily form $\mathrm{Ce}_{5} \mathrm{Si}_{4}$ is interesting and may be explained in terms of the molar volumes found in Table 1 . The free energy of formation is commonly written as $\Delta G=\Delta H f-T \Delta S$. In highenergy ball milling, the entropy term is often neglected as both $\mathrm{T}$ and $\Delta \mathrm{S}$ are small compared to $\Delta \mathrm{H}$. However, under high pressure conditions or in systems with large volume changes, the free energy of formation must account for these terms ${ }^{21}$.

The solid state reaction $\mathrm{Ce}_{3} \mathrm{Si}_{2}+2 \mathrm{CeSi}=\mathrm{Ce}_{5} \mathrm{Si}_{4}$ has $\Delta \mathrm{G}_{\mathrm{f}}=-4.97 \mathrm{~kJ} / \mathrm{mol}$ at reference temperature and pressure, and a volume change of $+4.95 \mathrm{~cm}^{3} / \mathrm{mol}$. With a negative free energy of formation, this reaction is thermodynamically likely to proceed. However, the reaction is driven by the milling media impacts, with an impact pressure estimated from closed form hertzian milling modeling ${ }^{22}$ to be 
approximately $5 \mathrm{GPa}$. Under these conditions, the large volume expansion associated with the formation of $\mathrm{Ce}_{5} \mathrm{Si}_{4}$ from the bordering line compounds $\mathrm{CeSi}$ and $\mathrm{Ce}_{3} \mathrm{Si}_{2}$ results in a positive free energy of formation for pressures exceeding $\Delta \mathrm{H}_{\mathrm{f}} / \Delta \mathrm{V}=950 \mathrm{MPa}$. The given reaction $\mathrm{Ce}_{3} \mathrm{Si}_{2}+2 \mathrm{CeSi}=\mathrm{Ce}_{5} \mathrm{Si}_{4}$ at $5 \mathrm{GPa}$ has a modified $\Delta \mathrm{G}_{\mathrm{f}}^{298 \mathrm{~K}, 5 \mathrm{GPa}}=+18.31 \mathrm{~kJ} / \mathrm{mol}$, which provides a thermodynamic argument for the experimental difficulty in forming $\mathrm{Ce}_{5} \mathrm{Si}_{4}$ in the impact-driven milling system studied.5.4 Time to MSR Ignition

Since MSR behavior was observed for the CeSi composition, CeSi was investigated further by milling at different speeds and at different powder loads. Changing the volume of milled powder produced a linear change in the time required for MSR ignition, which is in line with the recent results of Gotor ${ }^{23}$, who studied the Zn-Se system. However, milling Ce-Si at different speeds also resulted in a linear change in the ignition time, as shown in Figure 1, inset. This indicates MSR kinetics that depend only on the number of milling media impacts ${ }^{22,24}$ which at first seems to contradict the $\mathrm{rpm}^{3}$ dependence described by Gotor as being proportional to the mechanical dose absorbed by the powder.

However, this discrepancy may be resolved by considering the particle sizes involved. Gotor milled $\mathrm{Zn}$ and $\mathrm{Se}$ at -325 mesh, while we have milled $\mathrm{Ce}$ and $\mathrm{Si}$ at -40/+60 mesh. If we assume that the phenomenon of atomic level mixing during milling is driven by grain size refinement in the milled material, resulting in a mechanical dose dependence, then we may make use of the well-known empirical laws of grinding summarized by Hukki ${ }^{25}$ to estimate the actual dependence of grain refinement on mechanical dose. Huuki proposed a "solomnic settlement", a combined law of form

$$
d E=-C \frac{d x}{x^{f(x)}}
$$

where $x$ is the critical dimension of a comminuted material, $C$ is a material constant, and $f(x)$ describes some dependence of $d E$ on the current size. Rittinger's law predicts the energy required for particle size reduction in very small $(<10 \mu \mathrm{m})$ particles to be proportional to the new surface created and requires $f(x)=2$ in Equation 2. The relationship observed by Gotor for Zn-Se involves milling kinetics that depend on the energetic dose as in Rittenger's Law. Another form of Equation 2 with $f(x)=1$ is known as Kick's Law and covers the range of somewhat larger $(100-1000 \mu \mathrm{m})$ particles. In this regime, fracture, sheet thinning, and other forms of dimension reduction depend only on the number of times the particle is struck with an appropriate force, and this is the relationship observed in the Ce-Si system.

A caveat to note is that Hukki's combined law is empirically derived for brittle materials, and while work has been done to consider elastic deformation and fracture in terms of a combined law ${ }^{26}$, it does not appear that a satisfactory model currently exists to describe grain refinement in ductile materials during milling. That should not detract from the general applicability of the model in this instance, as the central point is that particle size reduction or grain refinement during milling is not inversely proportional to milling dose for relatively large starting particle size.

5.5 Phenomenological Model The phase content and particle morphology of milled cerium and silicon proceeds in a manner typical of ductile-brittle systems with the added complexity of an intermediate MSR event. When milling at $500 \mathrm{rpm}$, the system follows well-defined steps: 
1. $0-30$ minutes: Cerium is plastically deformed from $>100 \mu \mathrm{m}$ filings into $<10 \mu \mathrm{m}$ sheets

i. Formation of cerium / silicon laminate structure (Fig. 3c)

2. 30-70 minutes: Cerium and silicon undergo incomplete reaction in an MSR event (Fig. 1)

i. Ignition time linearly dependent on milling speed (Fig. 1, inset)

ii. Ignition time correlated to effective heat of formation at nominal composition (Fig. 6)

3. MSR: Cerium and silicon react to form an intermediate compound

i. Ce-rich compositions contain silicide and free silicon surrounded by cerium (Fig. 3a,b)

ii. XRD indicates $\mathrm{CeSi}_{2-\mathrm{y}}$ defect orthorhombic structure

iii. EDS indicates $\mathrm{Ce}_{2} \mathrm{Si}_{3}$ MSR product as well as $\mathrm{Ce}_{0.895} \mathrm{Si}_{0.105}$ eutectic

4. MSR-2 hours: Cerium quickly reacts with the silicide formed during the MSR

i. Broad peak in heat release by solid state reaction (Fig. 1)

6. ConclusionsAll cerium silicide line compounds save $\mathrm{Ce}_{5} \mathrm{Si}_{4}$ were successfully synthesized by mechanochemical processing of elemental cerium and silicon. The nominal composition $\mathrm{Ce}_{5} \mathrm{Si}_{4}$ could not be synthesized in this manner and remained a two phase mixture of $\mathrm{CeSi}$ and $\mathrm{Ce}_{3} \mathrm{Si}_{2}$ after 6 hours of milling at $500 \mathrm{rpm}$. The synthesis proceeded by means of a mechanically-induced self-propagating reaction to form a phase with the orthorhombic $\mathrm{CeSi}_{2-y}$ crystal structure and nominal composition $\mathrm{Ce}_{2} \mathrm{Si}_{3}$. The MSR event took place after a characteristic induction time that was shown to correlate with the effective heat of formation for each composition at the lowest melting eutectic. Microstructural evidence suggests that the reactants were partially or totally melted during MSR events. The MSR event was followed by a rapid solid state diffusion reaction between the $\mathrm{Ce}_{2} \mathrm{Si}_{3}$ compound and excess $\mathrm{Ce}$ and/or Si to form an essentially single phase product with the nominal starting composition. Some $\mathrm{Ce}_{3} \mathrm{Si}_{2}, \mathrm{CeSi}$ and $\mathrm{CeSi}_{2-x}$ powders were consolidated by spark plasma sintering, resulting in pellets of $95 \%$ or higher theoretical density and fine, equiaxed grain structure.

\section{Acknowledgments}

This project was partially supported by the Department of Energy under NEUP award \#00120690. Paul Lessing at the Idaho National Laboratory, Dan Osterberg and Bryan Forsmann at Boise State University, and Kolton Urso and Beata Tyburska-Püschel at University of Wisconsin-Madison all contributed helpful discussion during this project. 


\section{References}

[1] M. Kohgi, T. Satoh, K. Ohoyama, M. Arai, Competition Between the Kondo Effect and RKKY Interactions in $\mathrm{CeSi}_{x}$, Physica B 169 (1991) pp. 501-502.

[2] D. Souptel, G. Behr, W. Loser, A. Teresiak, S. Drotziger, C. Pfleiderer, CeSi2-delta single crystals: growth features and properties, J Cryst. Growth 269 (2004) pp. 606-616.

[3] M.V. Bulanova, P.N. Zheltov, K.A. Meleshevich, P.A. Saltykov, G. Effenberg, Cerium-silicon system, J. Alloy. Compd. 345 (2002) pp. 110-115.

[4] L.C. Wang, Q.Y. Dong, J. Lu, X.P. Shao, Z.J. Mo, Z.Y. Xu, J.R. Sun, F.X. Hu, B.G. Shen, Lowtemperature large magnetocaloric effect in the antiferromagnetic CeSi compound, J. Alloy. Compd. 587 (2014) pp. 10-13.

[5] H. Zhang, Y. Mudryk, Q. Cao, V.K. Pecharsky, K.A. Gschneidner, Y. Long, Phase relationships, and structural, magnetic, and magnetocaloric properties in the $\mathrm{Ce}_{5} \mathrm{Si}_{4}-\mathrm{Ce}_{5} \mathrm{Ge}_{4}$ system, J. Appl. Phys. 107 (2010) pp. 10.

[6] S. Pasebani, I. Charit, Y.Q. Wu, D.P. Butt, J.I. Cole, Mechanical alloying of lanthana-bearing nanostructured ferritic steels, Acta Mater. 61 (2013) pp. 5605-5617.

[7] C. Suryanarayana, Mechanical alloying and milling, Prog. Mater. Sci. 46 (2001) pp. 1-184.

[8] R.K. Viswanadham, S.K. Mannan, S. Kumar, Mechanical Alloying Behavior in Group-V TransitionMetal Silicides, Scripta Metall. 22 (1988) pp. 1011-1014.

[9] G. Le Caër, E. Bauer-Grosse, A. Pianelli, E. Bouzy, P. Matteazzi, Mechanically Driven Syntheses of Carbides and Silicides, J. Mater. Sci. 25 (1990) pp. 4726-4731.

[10] L. Takacs, Self-sustaining reactions induced by ball milling, Prog. Mater. Sci. 47 (2002) pp. 355414.

[11] Z. Munir, U. Anselmi-Tamburini, Self-propagating exothermic reactions: The synthesis of hightemperature materials by combustion, Mater. Sci. Rep. 3 (1989) pp. 279-365.

[12] S.V. Meschel, O.J. Kleppa, Standard Enthalpies of Formation of Some Carbides, Silicides and Germanides of Cerium and Praseodymium, J. Alloy. Compd. 220 (1995) pp. 88-93.

[13] A. Shukla, Y.B. Kang, A.D. Pelton, Thermodynamic assessment of the Ce-Si, Y-Si, Mg-Ce-Si and Mg-Y-Si systems, Int. J. Mater. Res. 100 (2009) pp. 208-217.

[14] C.C. Theron, O.M. Ndwandwe, J.C. Lombaard, R. Pretorius, First phase formation at interfaces: Comparison between Walser-Bene and effective heat of formation model, Mater. Chem. Phys. 46 (1996) pp. 238-247.

[15] P. Schobingerpapamantellos, K.H.J. Buschow, 2-Step Ferromagnetic Ordering of $\mathrm{Ce}_{2} \mathrm{Si}_{3}$-Delta, J. Alloy. Compd. 198 (1993) pp. 47-50.

[16] E. Houssay, A. Rouault, O. Thomas, R. Madar, J.P. Senateur, Metallurgical Reinvestigation of the Rare Earth Silicides, App. Surf. Sci. 38 (1989) pp. 156-161.

[17] Inorganic Crystal Structure Database, FIZ Karlsruhe, icsd.fiz-karlsruhe.de, Accessed 4/2014.

[18] F. K. Urakaev, Simulation of the Mechanically Induced Self-propagating Reactions: Theoretical 
Estimation for MSRs Ignition Time in Zn-S-Sn System, Combust. Sci. Technol. 186[1] (2014) pp. 34-46.

[19] C.C. Hsu, J. Ho, J.J. Qian, Y.T. Wang, Cerium Silicide Formation in Thin Ce-Si Multilayer Films, J. Vac. Sci. Tech. A 9 (1991) pp. 998-1001.

[20] R.D. Thompson, B.Y. Tsaur, K.N. Tu, Contact Reaction Between Si and Rare-Earth Metals, Appl. Phys. Lett. 38 (1981) pp. 535-537.

[21] E. Brosh, R.Z. Shneck, G. Makov, Explicit Gibbs Free Energy Equation of State for Solids, J. Phys. Chem. Solid. 69 (2008) pp. 1912-1922.

[22] P.P. Chattopadhyay, I. Manna, S. Talapatra, S.K. Pabi, A mathematical analysis of milling mechanics in a planetary ball mill, Mater. Chem. Phys. 68 (2001) pp. 85-94.

[23] F.J. Gotor, M. Achimovicova, C. Real, P. Balaz, Influence of the milling parameters on the mechanical work intensity in planetary mills, Powder Technol. 233 (2013) pp. 1-7.

[24] A. Iasonna, M. Magini, Power measurements during mechanical milling. An experimental way to investigate the energy transfer phenomena, Acta Mater. 44 (1996) pp. 1109-1117.

[25] R.T. Hukki, Proposal for a Solomnic Settlement between the Theories of von Rittinger, Kick, and Bond, Trans. Am. Inst. Min. Metall. Eng. 220 (1961) pp. 403-408.

[26] A. Thomas, L.O. Filippov, Fractures, fractals and breakage energy of mineral particles, Int. J. Miner. Process. 57 (1999) pp. 285-301. 
Figures and Captions



Figure 1: This figure shows $\Delta T$ (calculated from vessel parameters and measured $P$ and $T$, see text) versus milling time for the indicated compositions. The arrow points to sharp peaks in the data indicative of MSR events. The inset shows the milling time to MSR ignition for CeSi at different milling speeds with best fit line.

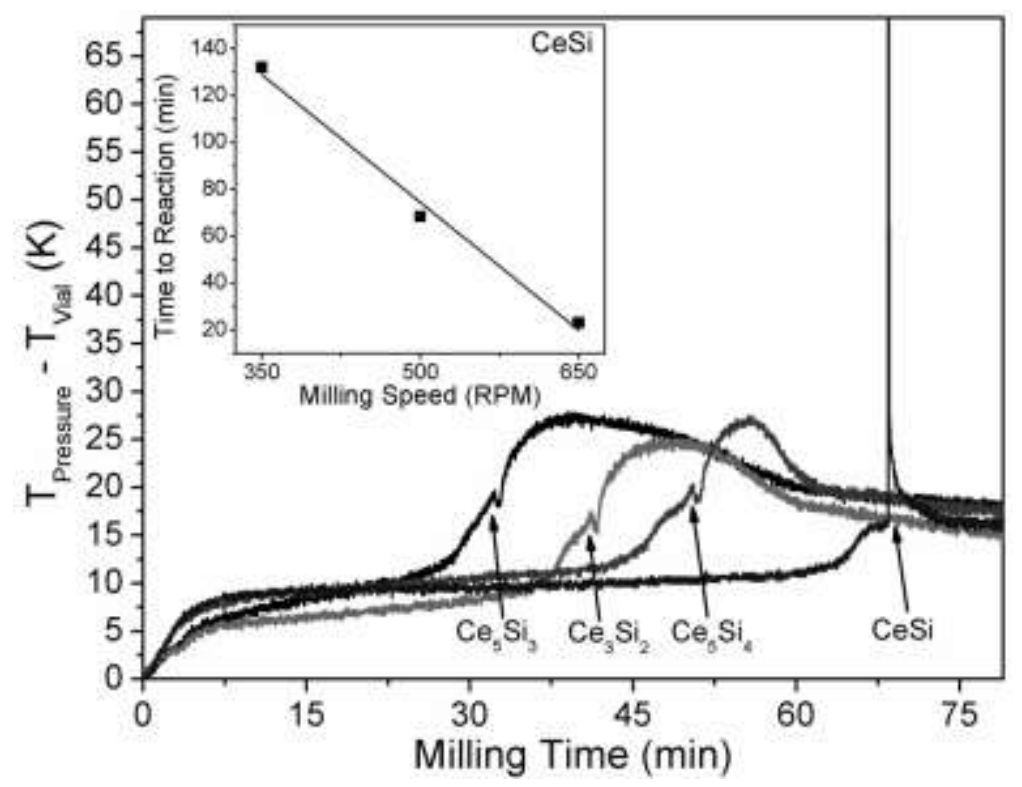




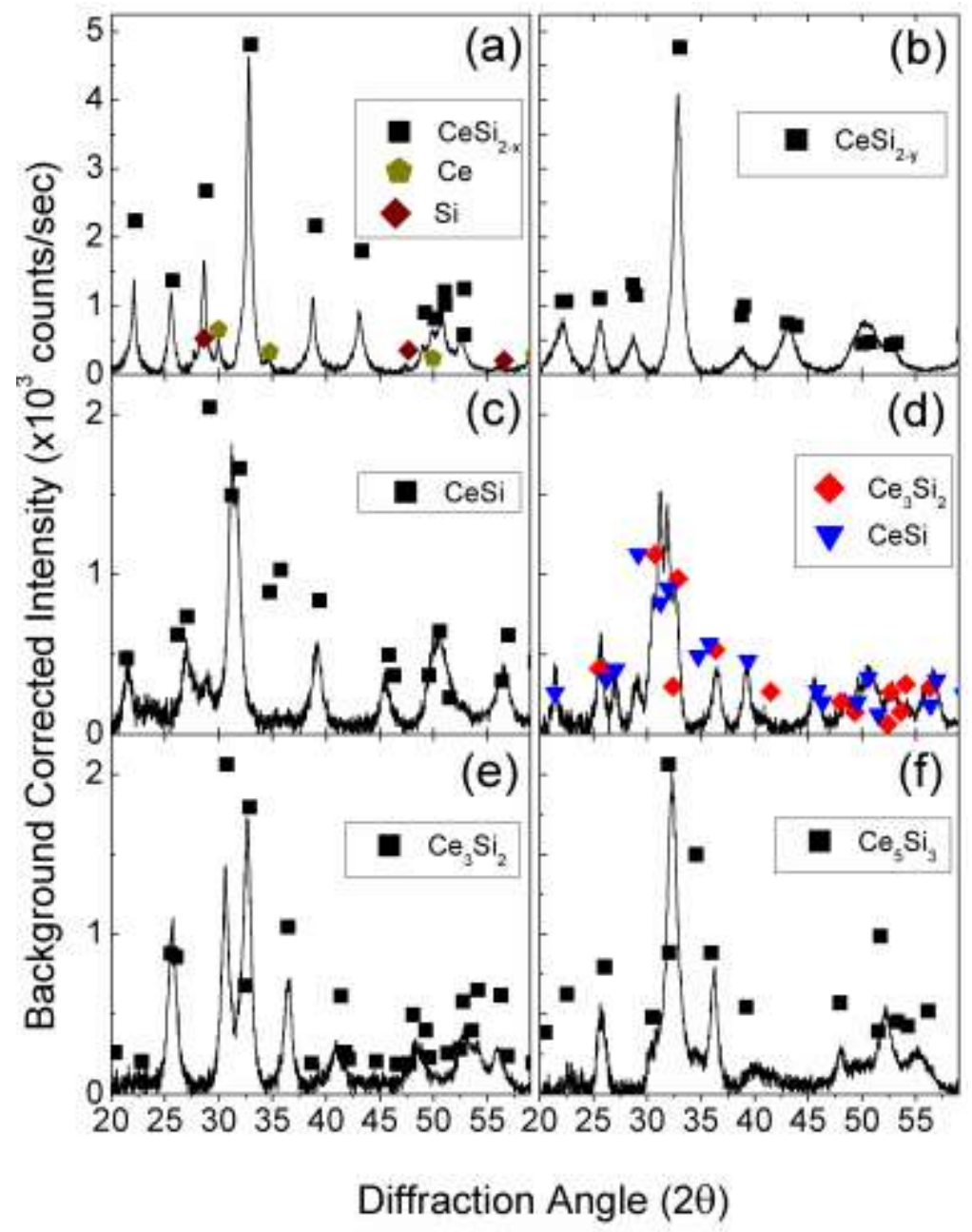

Figure 2: This figure shows XRD $2 \theta$ spectra collected after 6 hours of milling at $500 \mathrm{rpm}$ for the nominal compositions (a) $\mathrm{CeSi}_{2}$ (b) $\mathrm{CeSi}_{1.68}$ (c) $\mathrm{CeSi}$ (d) $\mathrm{Ce}_{5} \mathrm{Si}_{4}$ (e) $\mathrm{Ce}_{3} \mathrm{Si}_{2}$ (d) $\mathrm{Ce}_{5} \mathrm{Si}_{3}$. In each pane, the scatter points indicate expected peak locations as described in each pane's legend. The desired nominal composition phase is indicated in each pane by black squares and was obtained in all cases except $\mathrm{Ce}_{5} \mathrm{Si}_{4}(\mathrm{~d})$, which consisted of $\mathrm{CeSi}$ (red diamonds) and $\mathrm{Ce}_{3} \mathrm{Si}_{2}$ (blue down arrows). The $\mathrm{CeSi}_{2}$ (a) composition contained a slight amount of unreacted Ce (gold pentagons) and Si (maroon diamonds). Color online. 






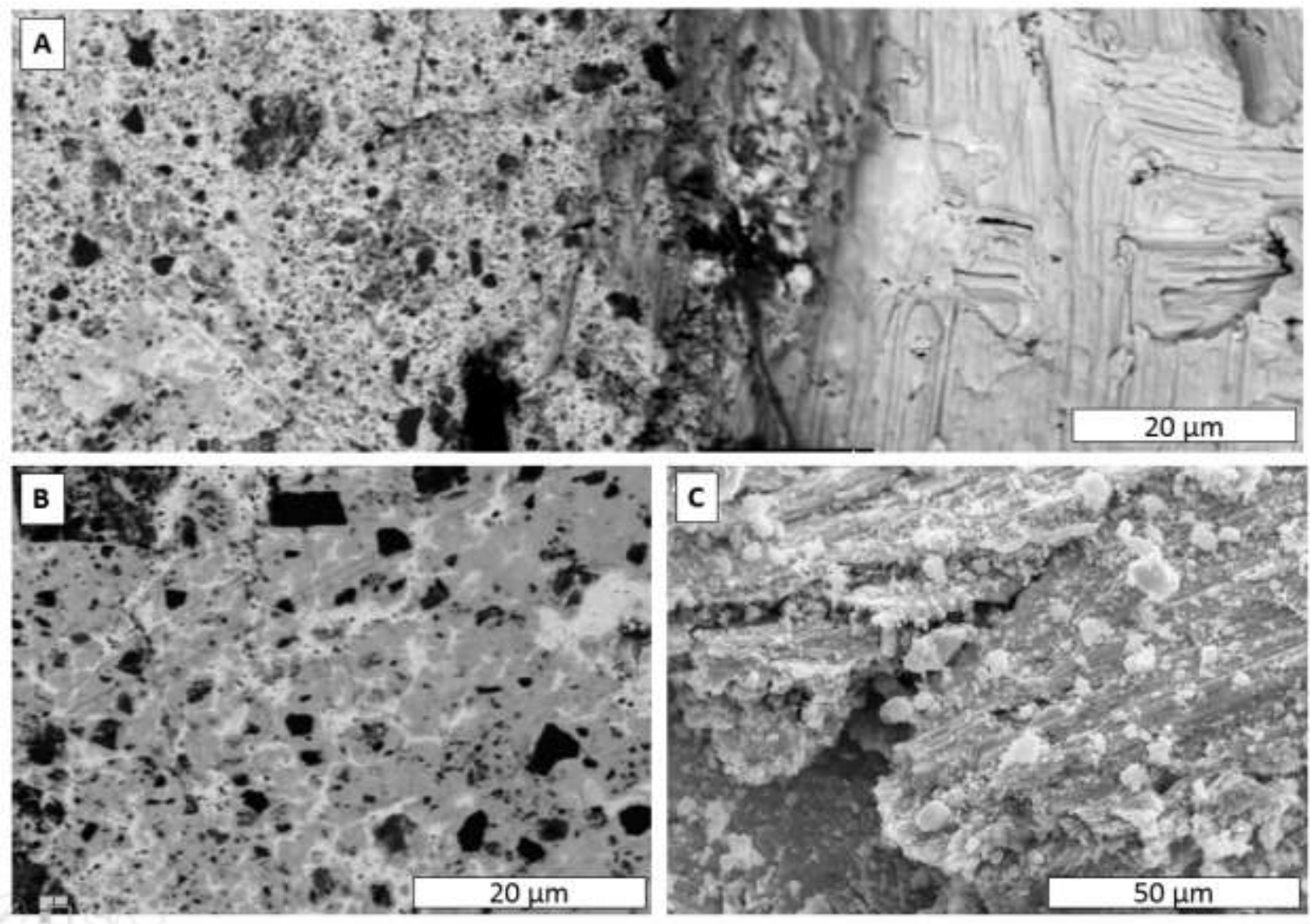

Figure 3: This figure shows SEM micrographs just before and after MSR in the $\mathrm{Ce}_{3} \mathrm{Si}_{2}$ composition. a) BSE panorama from a sectioned and polished fragment recovered directly after the MSR event. On the right side, a smooth Ce exterior implies melting during reaction, while moving toward the left reveals the inhomogeneous interior. b) BSE micrograph of a $\mathrm{Ce}, \mathrm{Ce}_{2} \mathrm{Si}_{3}$ and $\mathrm{Si}$ three-phase region from the same sample as A. c) SE micrograph prior to MSR event shows Si particles layered with Ce sheets. 


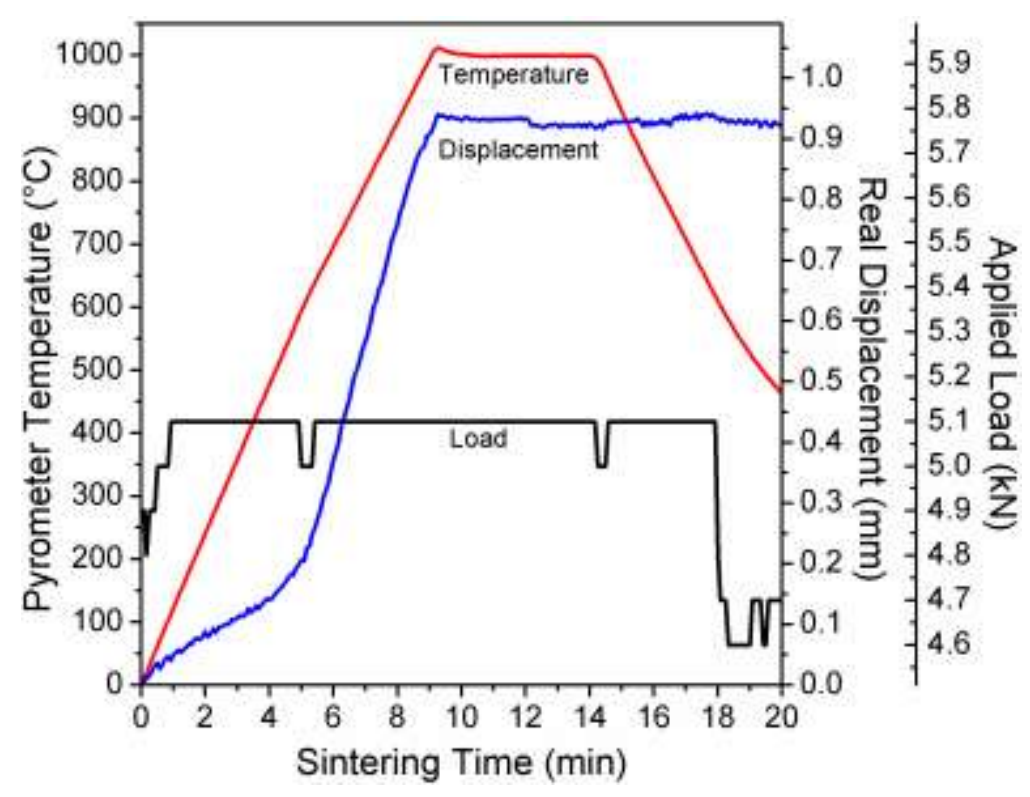

Figure 4: This figure shows a typical Spark Plasma Sintering experiment conducted with as-milled $\mathrm{Ce}_{3} \mathrm{Si}_{2}$ powder. The temperature was quickly raised to $1000^{\circ} \mathrm{C}$ at a constant $5 \mathrm{kN}$ load and held for 5 minutes before cooling to $600^{\circ} \mathrm{C}$ and releasing pressure.








Figure 5: SEM micrograph of a fracture surface in a $\mathrm{Ce}_{3} \mathrm{Si}_{2}$ sample prepared by ball milling followed by SPS at $1000 \mathrm{C}$ shows fine grain structure with a few small rounded pores at grain boundaries. 


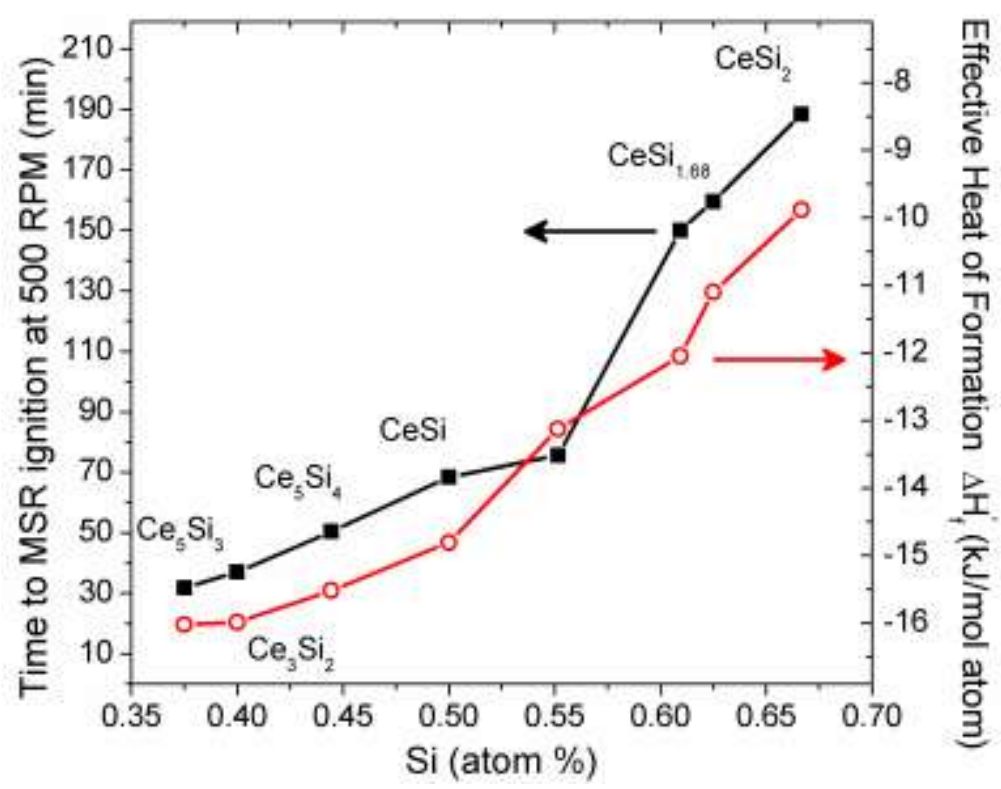

Figure 6: This figure shows the correlation of MSR ignition time ( $5 \mathrm{~g}$ load, $500 \mathrm{rpm}$ ) of all compositions studied (left axis) and the effective heat of formation of each composition at the $\mathrm{Ce}_{0.895} \mathrm{Si}_{0.105}$ eutectic (right axis).

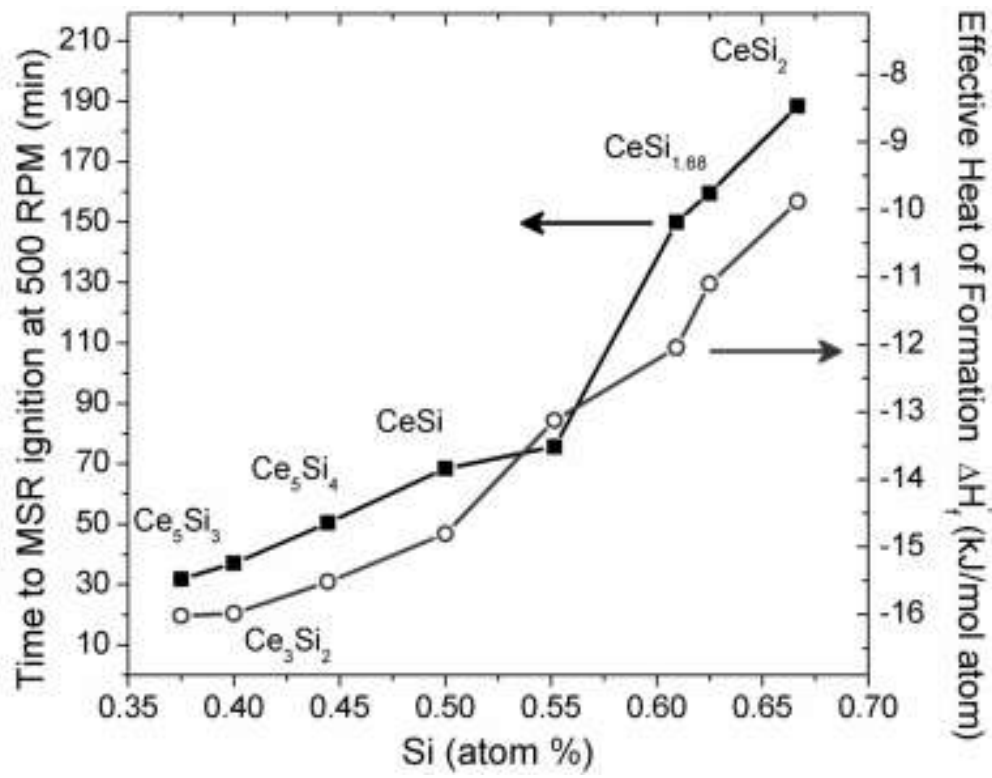

